\title{
INJURIES TO THE EYE
}

\author{
A R Elkington, P T Khaw
}

\section{History}

\begin{tabular}{|l|}
\hline Corneal abrasions \\
Foreign bodies \\
Radiation damage \\
Chemical damage \\
Blunt injuries \\
Penetrating injuries \\
\hline
\end{tabular}

An injury to the eye or its surrounding tissues is the commonest reason for attendance at the eye casualty department.

The history of how the injury was sustained is crucial as it gives clues to what should be looked for during the examination. If there is a story of any high velocity injury (particularly a hammer and chisel injury) a penetrating injury must be strongly suspected, and excluded. If there has been a forceful blunt injury (such as a punch) signs of a "blow out" fracture should be sought. The circumstances of the injury must be elicited and carefully recorded as these may have important medicolegal implications.

\section{Examination}

A good examination is vital if there is a history of eye injury. Specific signs must be sought or they will be missed. It is vital to test visual acuity both to establish a baseline value and to alert the examiner to the possibility of further problems, although an acuity of $6 / 6$ does not necessarily exclude serious problems-even a penetrating injury. The usual acuity may also have considerable medicolegal implications. Local anaesthetic may need to be used to obtain a good view, and the use of fluorescein is mandatory if an abrasion is not to be missed.

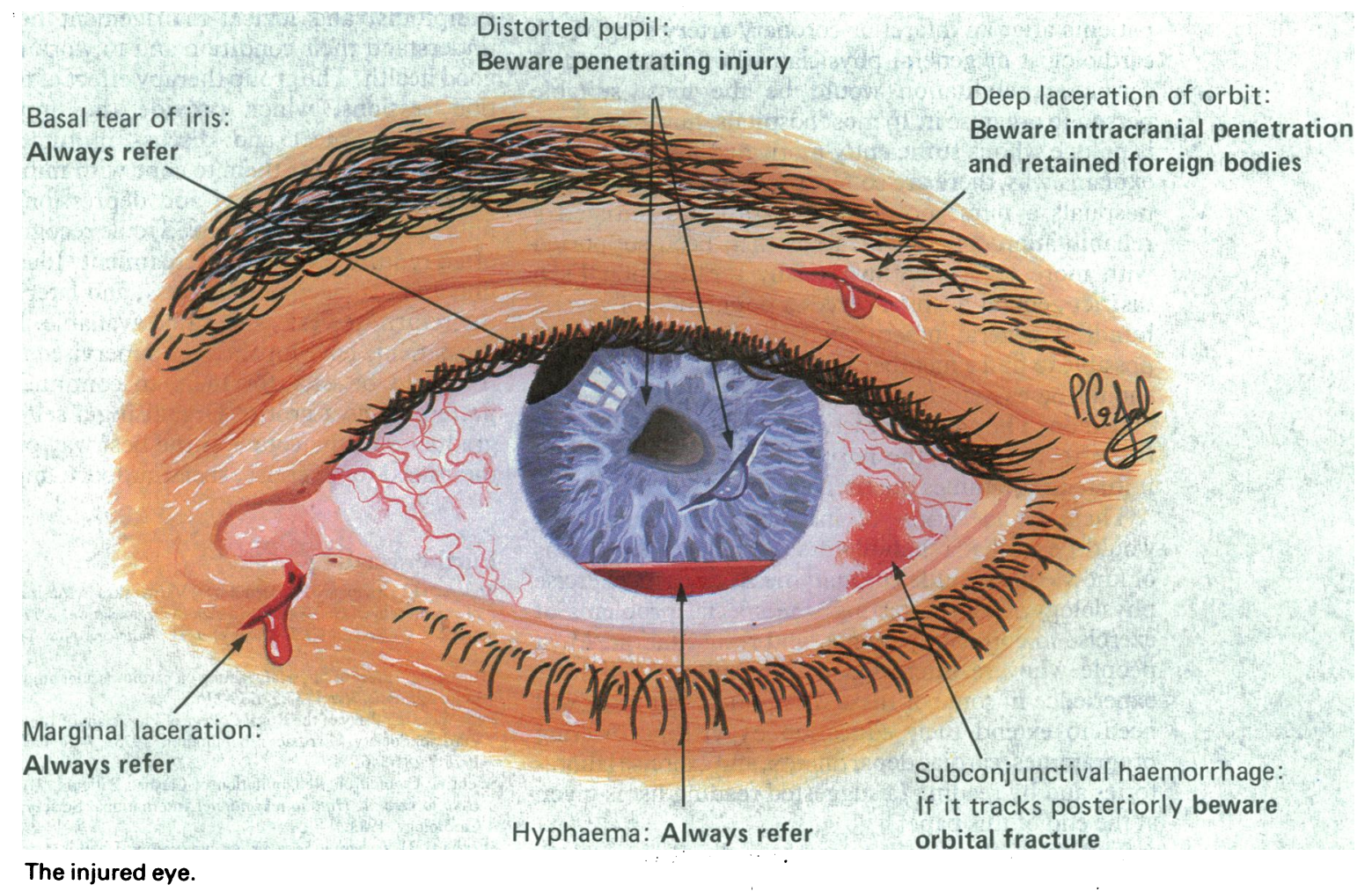




\section{Corneal abrasions}

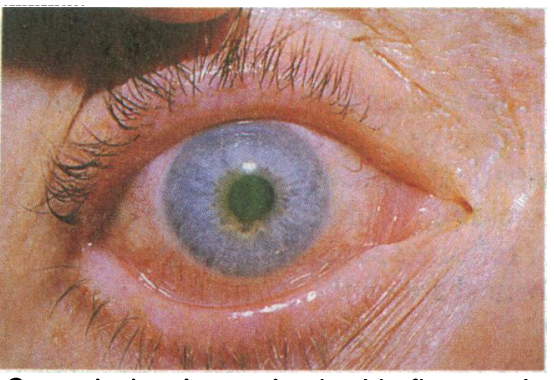

Corneal abrasion stained with fluorescein and illuminated with white light.

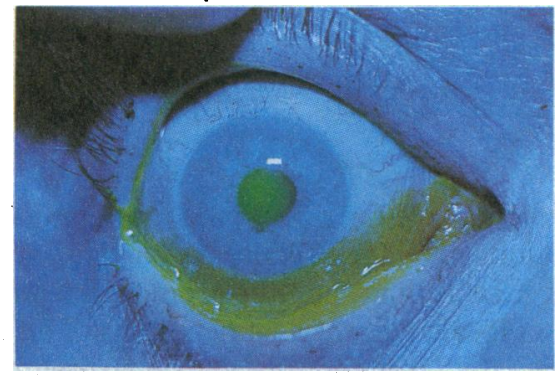

Corneal abrasion stained with fluorescein and illuminated with blue light.

\section{Foreign bodies}

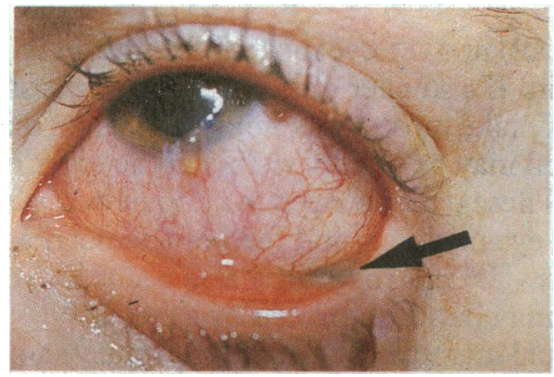

Lower lid gently pulled down to show a conjunctival foreign body. The cornea has also been perforated.
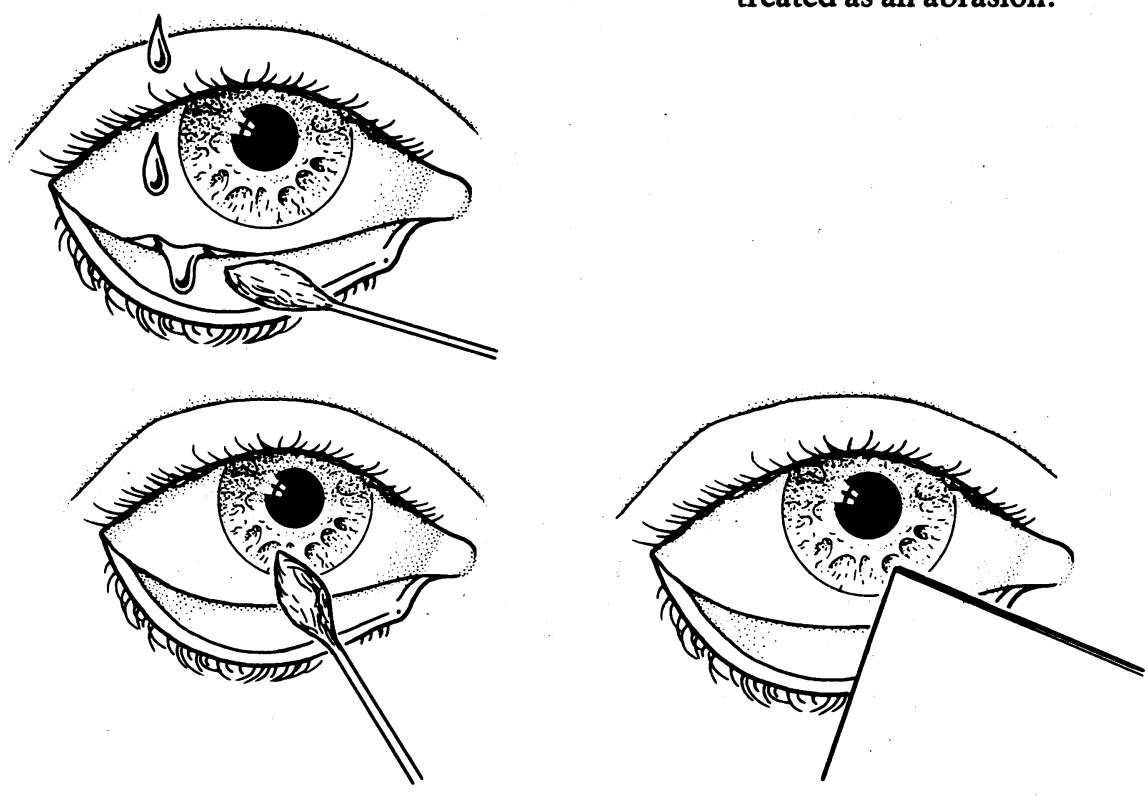

- Use local anaesthetic

If it is loose, irrigate

- If it is adherent, use a cotton wool bud or a piece of cardboard. 


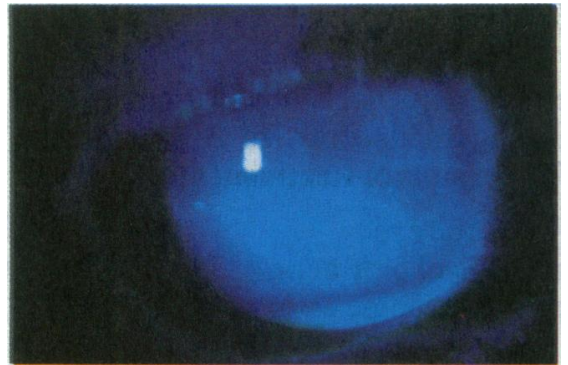

Cornea after welding damage stained with fluorescein and illuminated with blue light.

\section{Chemical damage}

Wash out immediately

Remove loose particles

Refer to ophthalmic department

beWARE alkalis
The commonest form of radiation damage occurs when welding has been carried out without adequate shielding of the eye. The corneal epithelium is damaged by the ultraviolet rays and the patient typically presents with painful, weeping eyes some hours after welding. Radiation damage can also occur after exposure to large amounts of reflected sunlight-for example, snow blindness. Treatment is as for a corneal abrasion.

If chemicals are splashed into the eye the eye should immediately be washed out with copious amounts of water. Alkalis are particularly damaging, and any loose bits such as lime should be removed from the conjunctival sac with the aid of local anaesthetic if necessary. The patient should then be referred immediately to an ophthalmic department. If there. is any doubt irrigation should be continued for as long as possible.

\section{Blunt injuries}
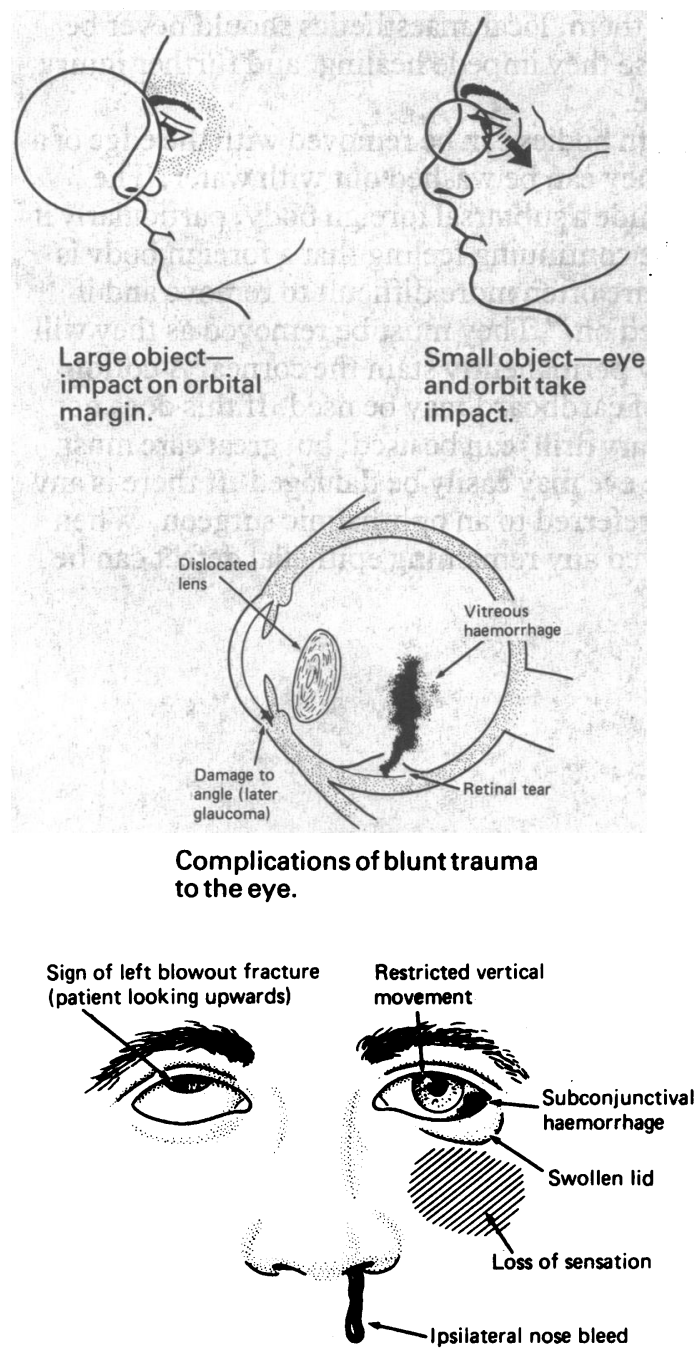

Signs of an orbital blowout fracture.
If a large object (such as a football) hits the eye most of the impact is usually taken by the orbital margin. If a smaller object (such as a squash ball) hits the area the eye itself may take most of the impact. Haemorrhage may occur and a collection of blood may be plainly visible in the anterior chamber of the eye (hyphaema). These patients need to be reviewed at an eye hospital as the pressure in the eye may rise, and further haemorrhages may need to be removed surgically. Haemorrhage may also occur into the vitreous or in the retina, and this may be accompanied by a retinal detachment. All patients with visual impairment after blunt injury should be seen in an ophthalmic department.

The pupil may also be damaged and react poorly to light. This is particularly important in a patient with an associated head injury, as this may be interpreted as - or mask - the dilated pupil that is suggestive of an acute extradural haematoma. The lens may be damaged or dislocated, and a cataract may develop. Damage to the drainage angle of the eye (which cannot be seen without a mirror contact lens and a slit lamp microscope) increases the chances of glaucoma developing in later life. If the force of impact is transmitted to the orbit an orbital fracture may occur (usually in the floor, which is thin and has little support). Clues to the presence of an inferior "blow out" fracture include diplopia, a recessed eye, defective eye movements (especially vertical), an ipsilateral nose bleed, and diminished sensation over the distribution of the infraorbital nerve. The fracture may need repair and these patients should be referred to an ophthalmic department.

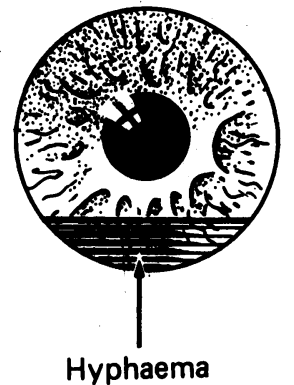

Hyphaema

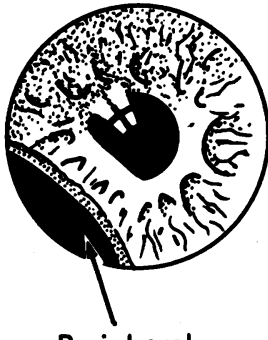

Peripheral tear in iris

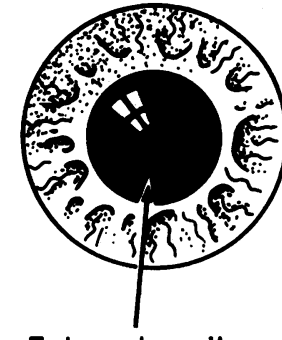

Enlarged pupil: damaged sphincter 

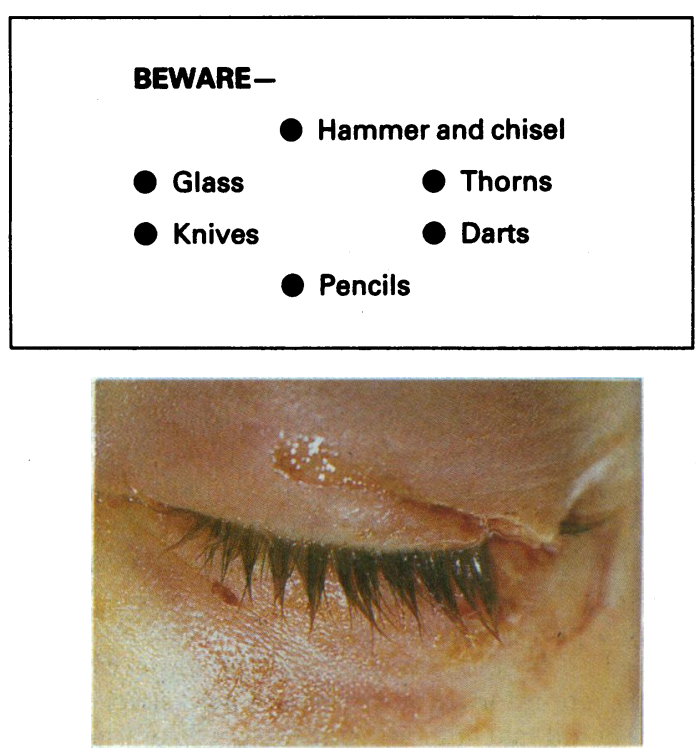

Lacerated eyelid.
Lacerations to the eyelids need specialist attention if:

The lid margins have been torn - these must be sewn together accurately.

The lacrimal ducts have been damaged - the cut ends must be reapposed.

There is any suspicion of a foreign body or penetrating eyelid injury - objects may easily penetrate the orbit and even the cranial cavity through the orbit.

Penetrating injuries of the eye can easily be missed because they may seal themselves, and the signs of abnormality are subtle. Any history of high velocity injury (particularly a hammer and chisel injury) should lead one strongly to suspect a penetrating injury. If there is any suspicion of a penetrating injury the eye should be examined very gently and no pressure should be brought to bear on the globe.

Signs to look for include a distorted pupil, cataract, and vitreous haemorrhage. The pupil should be dilated (if there is no head injury) and a thorough search made for an intraocular foreign body. If in any doubt, a radiograph of the orbit should be taken.

If the eye is clearly perforated it should be protected from any pressure and the patient sent immediately to the nearest eye hospital.

Mr A R Elkington, FRCS, is senior lecturer in ophthalmology, Southampton Eye Hospital, and Mr PT Khaw, MRCP, senior registrar, Moorfields Eye Hospital, London.

\section{WORDS}

viRus. Advances in our understanding of diseases present difficulties with nomenclature. With each stage of improved understanding there is a tendency to coin neologisms. The old names, which may have been based on fallacious beliefs or on incomplete knowledge of the causes, clinical features, or pathology, are no longer descriptively appropriate. There are, nevertheless, diseases that retain their old names despite total rejection of the archaic concepts implied in their nomenclature. Malaria and influenza, for example, are no longer believed to be due to "bad air" or astral "influence." Similarly, "virus" is a veritable onomastic chameleon. Its meaning has changed throughout the ages in accordance with changes in current concepts of certain diseases.

The earliest English use of the word vIRUS stemmed from the Latin virus, (slime, poisonous liquid, venom, stench). "Virus," in English, meant "venom such as emitted by a poisonous animal"; also used figuratively, according to the Oxford English Dictionary (OED), which quotes: 1599, "You ... . have ... spit out all the virus and poyson you could conceiue in the abuse of his person." 1702, "The story of Cleopatra . pouring the virus of an Asp into a Wound made in her Arm by her own teeth." In a medical context, the $O E D$ quotes: 1728 , "Virus... a corrosive or contagious pus."

Centuries ago the epidemiology of contagion was vaguely and somewhat unevenly recognised. J B van Helmont's belief (1626) that these diseases were due to invasion of the body by an army of alien beings ${ }^{1}$ was merely one of several contemporary unsubstantiated theories. It was generally believed that poisonous material emanated from a patient, and that it entered the body of the next victim. Regarded as a poison, it was often called "virus," with which term it was synonymous. The $O E D$ quotes early medical usage: 1799, "canine virus"; 1800, "The pustules . . . contain a perfect Small-pox virus"; 1826, "virus mixed with the saliva of the rabid animal." In these examples "virus" meant a communicable poison, and it is entirely co- incidental that they relate to conditions that are due to viruses in the modern sense. Hooper, in 1839 , defined "virus" as "any matter which is the product of disease, and is capable of producing that disease in a healthy individual by inoculation or absorption through the cuticle... thus we speak of the virus of small-pox, of the venereal virus, \&c."2 The influence of Jenner is noticeable here, but the nature of the "virus" remained a mystery. In 1843 Oliver Wendell Holmes, in The Contagiousness of Puerperal Fever, wrote, "a most fearful morbid poison is often generated in the course of this disease."

The first ray of light on the transmissibility of disease by micro-organisms emanated from the work of Louis Pasteur and Robert Koch in the third quarter of the nineteenth century with the establishment of pathogenic bacteria as agents of contagion. Despite the veritable explosion of discovery in bacteriology that occurred in the ensuing decades, this newly acquired knowledge did not penetrate to every nook and cranny of the medical establishment. Richard Quain's medical dictionary, in 1893, defined "virus" as "any kind of contagious material." 3 An inkling of what was happening did, however, reach the author of the entry on "contagion" in this dictionary. In eight pages of small type filled with verbose padding he refers to "various specific matters which effect contagion in the living body... they show themselves capable of self-multiplication... which strongly suggest that perhaps all contagia are things endowed with life."4

Despite the discovery that many diseases were caused by bacteria, there remained several diseases in which no relevant micro-organisms were identifiable. Yet material from infected tissue could be passed through the exceedingly fine pores of porcelain filter candles and the filtrate could transmit the disease. D Ivanovski was the first to do this in 1892 , using material from tobacco mosaic diseased plants. In 1902 Löffler and Frosch repeated the experiment with foot and mouth disease of cattle. Thereafter a number of similar experiments were performed with diseases affecting humans. Until the 1930s these infective agents were called filter passing viruses. Here we still have the term "virus" used for a non-bacterial unidentified infective agent, but by then there was a strong suspicion that we were dealing with a group of very small microorganisms. Their particulate nature was established by W J Elford who used graded filter membranes of known pore size. The invention of the electron microscope established the size and shape of these particles, and showed their self propagation within living host cells. This brings us up to modern times. The fourth volume of the $O E D$ supplement (1986) defines a virus as "an infectious organism... lacking any intrinsic metabolism and usually comprising a DNA or RNA core inside a protein coat." It has come a along way from being a "poyson."

The adjective of virus is "viral," as indeed most "-us" words of Latin origin take "-al" adjectivally. But the adjective of virus might have been "virulent," since the Latin virus has virulentus for its adjective. But "virulent" has pre-empted "viral." The adjective "virulent" was established in the days when "virus" meant poison.

It has to be said with regret that the lay public has adopted "virus" with little or no understanding. The term is thus misused for any transitory feverish indisposition. "It must be a virus" trips effortlessly from the lips. On this level I may close with a story of similar usage in junior hospital circles in the 1960s. There was much talk about a mysterious condition, probably viral, called Ataloia fever. Never heard of it? Ah, There's A Lot Of It About.

1 Harre R. Great scientific experiments. Oxford: Oxford University Press, 1983:97.

2 Hooper R. Lexicon medicum. 7th ed. London: Longman, Orme, 1839:1356.

3 Quain R, ed. A dictionary of medicine. London: Longmans, Green, 1893:1749.

4 Simon J. Contagion. In: Quain R, ed. A dictionary of medicine. London: Longmans, Green, 1893:286. 